\title{
Vida campesina y modelo de desarrollo: configuraciones de despojo/ privilegio en el norte del Cauca
}

\author{
Peasant Life and Development Model: Configurations of \\ Dispossession/Privilege in Northern Cauca
}

\author{
Alhena Caicedo Fernández \\ Universidad de los Andes \\ a.caicedo@uniandes.edu.co
}

\begin{abstract}
RESUMEN
Este trabajo estudia la vida campesina desde una aproximación cualitativa que contribuye a la comprensión de sus formas de subalternización en las últimas décadas. La investigación se concentra en la historia de los campesinos negros de dos veredas del municipio de Suárez: Pureto y La Toma, situadas al norte del departamento del Cauca, escenario de múltiples formas de despojo. Proponemos analizar la configuración regional como efecto del despliegue de un modelo de desarrollo que se ha articulado a partir de diferentes dispositivos de generación y ocultamiento del despojo, así como de producción de privilegios en distintas escalas.
\end{abstract}

Palabras clave: campesinos afro, despojo/ privilegio, ilegalidad, modelo de desarrollo, norte del Cauca.

\begin{abstract}
This paper explores peasant life from a qualitative standpoint in order to contribute to the understanding of the different forms of their subalternization in the last decades. The research is centered in the case of black peasants in two towns of the Suarez municipality, in the northern Cauca department: Pureto and La Toma, scenario of multiple forms of dispossession. We propose to analyze the regional configuration as an effect of the ways in which a particular development model has unfolded in the area, articulating different techniques that generate and conceal dispossession, as well as the production of privilege at multiple scales.
\end{abstract}

Keywords: Afro peasants, dispossession/privilege, illicitness, development model, North of Cauca. 


\section{Introducción ${ }^{1}$}

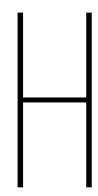

ace un par de años en el Centro de Pensamiento RaizAL comenzamos un ejercicio colectivo que busca ampliar el contenido de la noción de despojo. Partimos de una necesidad sentida de hacer del despojo un concepto denso, en contravía del uso simplificado y coyuntural que se le ha dado al término en escenarios tan disímiles como la Ley de Restitución de Tierras, los discursos de los movimientos sociales en contra del extractivismo y las demandas del Centro Democrático ${ }^{2}$ frente a la resolución de La Haya en el caso del archipiélago de San Andrés ${ }^{3}$, entre otras versiones. A nuestro modo de ver, el despojo funciona como un patrón de poder profundamente imbricado en la formación social colombiana, por lo que decidimos elaborar una conceptualización que diera cuenta de la persistencia de múltiples formas de desigualdad en la larga duración, a la luz de las distintas investigaciones que llevamos a cabo en diferentes regiones del país.

Este trabajo es parte de una experiencia de cuatro años de acompañamiento e investigación colaborativa entre el equipo de RaizAL y algunos consejos comunitarios ${ }^{4}$ del norte del Cauca que vienen construyendo sus planes de vida. A partir de un estudio de caso sobre campesinos negros, este artículo se pregunta por la historia de los pobladores del municipio de Suárez, Cauca, donde la vida campesina sobrevive a múltiples formas de despojo. Nos acercamos a la vida campesina desde una perspectiva etnográfica para reconocer sus formas de invisibilización y subalternización, así como sus articulaciones con el modelo de desarrollo regional, su despliegue en la larga duración y sus efectos. Nuestra intención es profundizar en los procesos históricos de configuración regional desde procesos locales; por ello partimos de pensar la región como una producción

1 Este artículo es producto de la investigación en curso titulada "Nación y diferencia: usos sociales de la cultura". Asimismo, es fruto del trabajo colectivo adelantado por el Centro de Pensamiento Latinoamericano RaizAL, en el municipio de Suárez (Cauca), y de las reflexiones del seminario permanente que ha construido esta red de investigadores en los últimos años.

2 Partido político representativo de la derecha en Colombia.

3 Se hace referencia a la resolución de la Corte Internacional de Justicia de La Haya (2012) que reconoce la soberanía nicaragüense sobre parte del territorio marítimo del archipiélago de San Andrés, perteneciente a Colombia. Esto generó una fuerte crítica al Gobierno por parte del Centro Democrático que no dudó en calificar el incidente como "despojo".

4 Figura étnico-territorial, derivada de la Ley 70 de 1993, que reconoce el derecho de las comunidades afrocolombianas al territorio colectivo y al gobierno propio de ese territorio. Aunque la figura solo aparece reglamentada en el caso del litoral pacífico, muchas comunidades negras que habitan otras regiones vienen solicitando el reconocimiento formal de los consejos y de la titulación colectiva. 
histórica cuyas formas de configuración interna están en permanente disputa (Van Young 1991).

Consideramos el despojo y el privilegio como categorías indisociables que funcionan de forma relacional como dos caras de una misma moneda. Por despojo entendemos la pérdida, ruptura o corte de una relación social significativa para la reproducción de la vida, por la acción arbitraria de otro (RaizAL 2016a). Siguiendo a Bourdieu (2012), consideramos el privilegio como el resultado de las ventajas derivadas de la puesta en juego de ciertos capitales, en contextos específicos. Dichas ventajas se concretan en la capacidad de tomar decisiones sobre la propia vida, pero principalmente en la de decidir sobre la vida de otros. La relación despojo/privilegio supone una forma de poder, una geometría particular que jerarquiza la relación entre quien decide y los otros sobre quienes se decide (RaizAL 2016b). Lejos de pretender hacer de esta relación un enunciado a priori, nos interesa entender cómo se produce este vínculo complejo, que no es directo ni inmediato, y que suele disponer de formas de ocultamiento, por lo cual debe ser identificado en cada contexto histórico y espacial particular. También queremos rastrear el carácter productivo del despojo/privilegio: qué efectos concretos genera, cómo se legitima y cómo reconfigura relaciones sociales que, a su vez, alimentan nuevas disputas por la hegemonía. En efecto, el estudio del despojo se cruza con el análisis de los procesos hegemónicos, de la construcción de memorias históricas y de conformación de subjetividades sociales (RaizAL 2016a).

En ese sentido, la noción de desigualdad es fundamental para definir el despojo/privilegio. Entendemos la desigualdad como una distribución diferencial de insumos estratégicos en una formación social determinada (Reygadas 2008). Dicha distribución puede configurar mecanismos de despojo y privilegio concretos, lo que no quiere decir que el despojo/privilegio se reduzca solo al hecho puntual del despojo de algo o al privilegio acerca de algo. El acumulado de desventajas históricas que recaen en unos sujetos (que pueden ser de muchos tipos de acuerdo con la formación social: racialización, marginalización, ilegalización, etc.) genera condiciones de desigualdad persistente que propician otras formas de despojo concretas. En otras palabras, el despojo no solo se produce por la desigualdad sino que además la alimenta, favoreciendo situaciones que reproducen nuevas formas de despojo; de manera similar, el privilegio tiende a acumular otros privilegios en el tiempo, que producen formas de desigualdad que derivan en otras formas de privilegio (RaizAL 2016). Asimismo, como efecto de las diversidades en tensión, las desigualdades son múltiples y en muchos casos hasta contradictorias (Reygadas 2008). Por tanto, la expresión de las desigualdades no siempre tiene los mismos efectos. Las condiciones históricas y sociales que 
en un momento específico tiene una formación social determinan los grados de legitimidad o ilegitimidad de las desigualdades, y generan disputas de sentido entre actores sociales que se dirimen de formas disímiles (Scott 1976).

Así las cosas, un primer punto a tener en cuenta es la necesidad de una perspectiva no reduccionista en el análisis, que dé cuenta de los complejos entramados económicos, políticos y culturales que constituyen la vida campesina en una región. Considerando las complejidades históricas y sociológicas de la definición de lo campesino (Edelman 2013), entendemos vida campesina como la expresión práctica y cotidiana de una ecología de la vida propia de la gente rural que habita una región particular, y en la que se integran relaciones territoriales, políticas, económicas y culturales (Gudeman 2013; Ingold 2000). Hablar de vida campesina nos permite dejar de lado nociones de la campesinidad centradas exclusivamente en la dimensión productiva y llamar la atención sobre el entramado de relaciones socioecológicas que constituyen estos modos de vida y cotidianidad. También, nos permite identificar críticamente estereotipos construidos sobre versiones esencializadas de la campesinidad y su lugar en los procesos de subalternización. De acuerdo con Salgado (2002), una de las representaciones sociales recurrentes sobre los campesinos, en la academia colombiana, en la política pública e incluso en los mismos movimientos sociales, tiene que ver con su asimilación a una idea de tradición opuesta a la noción hegemónica de modernidad. Esta dicotomía ha servido durante décadas, no solo como oposición conceptual sino también moral, para desvirtuar modos de vida y visiones de futuro propios de la ruralidad, a favor del ideal homogeneizante y teleológico de la modernización urbanocentrada.

En ese sentido, resulta importante advertir que la idea de modernidad, y sobre todo la de modernización, entendida aquí como aquellos modelos que funcionan como componentes de articulación de modernidad (Das y Poole 2008), actúan como dispositivos de poder que se han concretado de diversas formas en la historia regional. La "modernización”, como el "desarrollo", han sido enunciados discursivos poderosos que han guiado las políticas de intervención regional con fuertes impactos en las vidas campesinas. Por eso, dar cuenta de sus efectos no solo pasa por ubicar las formas de circulación de los enunciados y las narrativas, sino sobre todo por entender su apropiación práctica en la vida cotidiana y en la producción de subjetividades. En el caso del norte del Cauca, despojo y privilegio han sido constitutivos de un modelo de desarrollo cuya lógica se puede rastrear en la larga duración y donde la ilegalidad y la marginalización han desempeñado un papel central como dispositivos de ocultamiento del despojo, así como de la producción de privilegios que el mismo modelo de desarrollo regional genera, y a partir de los cuales se ha configurado históricamente esa región. 
Este artículo se divide en cuatro partes. Partimos de una breve caracterización histórica de la región del norte del Cauca y, en especial, de la subregión del alto Cauca donde se ubica el municipio de Suárez, con el fin de mostrar particularidades del proceso de poblamiento y de la configuración regional en el último siglo. Posteriormente, nos detendremos en la construcción de la hidroeléctrica de Salvajina en los años ochenta del siglo pasado, como un hito en la historia de modernización del norte del Cauca, pero también del despojo de sus pobladores. En una tercera parte profundizaremos en dos localidades del municipio de Suárez, Pureto y La Toma, que enfrentaron cada una de manera particular el despojo/privilegio generado por Salvajina y sus efectos, y que han tenido que sobrellevar la emergencia de dos formas de economía ilegal presentes en la región: la siembra de coca y la minería del oro. En cada caso nos interesa dar cuenta de las modalidades de despojo/privilegio y sus formas de articulación con mecanismos de reproducción de la desigualdad, como la marginalización y la ilegalización. Finalmente, consideramos importante mostrar las maneras mediante las cuales estos pobladores afrontan la situación a través de figuras organizativas como los consejos comunitarios, que no solo responden a dinámicas propias del multiculturalismo sino que a su vez señalan el carácter productivo del despojo/privilegio en la región.

\section{La cuenca alta del río Cauca en el norte del departamento}

El norte del Cauca es una región que cobija parte de la cuenca alta del río Cauca y la apertura de su valle geográfico. En términos político-administrativos, cubre varios municipios del norte del departamento y del sur del Valle. Se divide en dos subregiones: la cuenca alta o parte de ladera, y la zona plana del valle. En la primera se ubica el municipio de Suárez, con una población actual de 19.000 habitantes, de los cuales el 58,2\% se identifica como afrocolombiano o negro y el $21,2 \%$, como indígena. El $81,52 \%$ es rural y se dedica a la agricultura y a la minería artesanal ${ }^{5}$.

En los últimos doscientos años, el norte del Cauca se ha caracterizado por una importante diversidad étnica y una alta movilidad demográfica (Almario

5 Datos tomados del Plan Municipal de Desarrollo de Suárez, Cauca 2016-2019 y del DANE. 
2013; Aprile-Gniset 1994; Rojas 1985; Urrea et al. 2010, entre otros). De acuerdo con Michael Taussig y Anna Rubbo ([1975] 2011), la región se configura a partir de una segregación espacial e histórica de poblaciones que tiene un importante componente étnico y racial, y que se constituye en una topología moral por el peso de las clasificaciones étnico-raciales en las jerarquías de poder que se inscriben en el paisaje, a pesar de la movilidad de la gente: indígenas en las zonas altas, afrodescendientes en la zona plana y de piedemonte, y mestizos distribuidos en las tres, con énfasis en las laderas. Las investigaciones sobre las dinámicas económicas señalan la persistencia histórica de relaciones de producción racializadas (Aprile-Gniset 1994) y de las tensiones generadas alrededor del problema de la tierra y sus usos en el último siglo (Taussig [1980] 1993; Taussig y Rubbo 2011; Urrea et al. 2010).

Desde el siglo XVI, las minas cercanas a Popayán contaron con población esclavizada para la explotación de oro (West 1972). A finales del siglo XIX y al menos hasta los años treinta del XX, el norte del Cauca presenció la transformación de las antiguas haciendas esclavistas en haciendas dedicadas a la agricultura comercial que se alternaban con parcelas campesinas de negros, mulatos y libres $^{6}$ (Friedemann 1976; Taussig y Rubbo 2011). En la cuenca alta, donde se ubican actualmente los municipios de Buenos Aires y Suárez, se asentaron familias descendientes de los esclavizados de minas como Gelima y Honduras. La colonización se incrementó a comienzos del siglo XX con la llegada de más familias negras en busca de tierras baldías hacia la cordillera Occidental. La migración de población mestiza e indígena desde la cordillera Central y el sur del departamento hacia estos dos municipios creció con la construcción del ferrocarril de Cali a Popayán en los años veinte, el arribo de la Asnazú Gold Dredging Limited dedicada a la minería del oro en los treinta y la violencia bipartidista de los cuarenta (Ararat et al. 2013).

En los años sesenta, el norte del Cauca sufrió fuertes cambios a causa de la agenda de modernización introducida por las élites regionales asentadas en Cali en la zona plana; por un lado, la construcción de vías e infraestructura y, por otro, la intensificación de la producción agroindustrial de caña de azúcar. Estos procesos promovieron la monopolización de la tierra en el valle, lo que generó una progresiva expulsión de población negra hacia la ladera o su confinamiento en reductos poblados como Guachené, Puerto Tejada y Villarrica. Posteriormente,

$6 \quad$ Luego de decretarse la abolición de la esclavitud en 1851, la gente negra dedicada a la minería, la ganadería y la agricultura se convertiría en aparcera y pasaría progresivamente a una economía más campesina cuando logró acceder a la tierra, mediante la colonización de baldíos en las laderas de la cordillera, ya entrado el siglo XX. 
en la década de los noventa y gracias a la Ley Páez ${ }^{7}$, se instalaron allí los parques industriales y zonas francas, a la vez que se dio una fuerte urbanización jalonada desde Cali y su área metropolitana (Urrea et al. 2010, 15).

Durante el último siglo, el modelo de desarrollo empresarial regional del valle del río Cauca ha estado impulsado principalmente por la agroindustria cañera. Se trata de un modelo de acumulación de riqueza reconocido por las élites nacionales como muy exitoso que, sin embargo, ha demostrado generar un alto grado de desigualdad (Pérez y Álvarez 2009; Vanegas y Rojas 2011). En parte como resultado de las políticas de planeación regional, este modelo se elaboró y agenció de arriba hacia abajo por un gremio empresarial de la élite regional para el Valle, y se extendió hacia otras áreas como el norte del Cauca, que aparece, así, como un escenario periférico de despliegue de dicho modelo con centro en Cali, que se considera el único legítimo para la región y referente para otras regiones del país.

\section{El efecto Salvajina}

En los años setenta, la cuenca alta del Cauca fue epicentro de importantes proyectos de infraestructura que incidieron directamente en las dinámicas locales de los municipios de ladera. Por un lado, aparecieron los proyectos de fomento a la tecnificación del cultivo de café, impulsados por el Comité de Cafeteros y la Corporación Autónoma Regional del Valle del Cauca (CVC) ${ }^{8}$. Por otro lado, se inició el primer proyecto de infraestructura multipropósito del país: el represamiento del río Cauca y la construcción de la hidroeléctrica de Salvajina entre 1979 y 1985. Salvajina fue una iniciativa agenciada por el Estado y la empresa privada a través de la CVC, que se constituyó en la herramienta institucional para agenciar el plan de desarrollo económico regional formulado en 1953 por la recién creada

7 La Ley Páez es una medida de activación económica e incentivo a la industria que surgió a raíz del desastre ocasionado por el desbordamiento del río Páez en 1994, en la región de Tierradentro en el Cauca. Mediante esta ley se promueve la implantación de parques industriales y zonas francas en la zona plana del norte del Cauca (en una región que no fue afectada por el desastre y que se ubica al otro lado de la cordillera Central). Las empresas allí asentadas gozaron de exenciones tributarias por un periodo de diez años a cambio de generar empleo local. La evaluación de los efectos de la Ley Páez ha sido controversial (véanse Alonso y Lotero 2006 y Vanegas y Rojas 2011). nidense en temas de planificación económica que sentó las bases del plan que regiría el desarrollo del Valle del Cauca. 
Comisión de Planeación Departamental (Escobar 1998). La primera fase de gestión de la CVC se orientó a la construcción de las hidroeléctricas de Anchicayá, Calima y Salvajina. Esta última, conocida como Proyecto de Regulación del Río Cauca, tenía como propósito el represamiento del río, la regulación de su caudal y la puesta en funcionamiento de una hidroeléctrica que alimentara el departamento del Valle (CVC 2004). Aunque los estudios se iniciaron en la década de los cincuenta, las obras solo comenzaron a finales de los setenta con la adecuación de vías y la construcción del muro de contención en la parte alta del actual municipio de Suárez. Con el represamiento del río Cauca se buscaba controlar las inundaciones que afectaban la zona plana dedicada al monocultivo de caña y contribuir así a la productividad de la agroindustria azucarera, la cual estaba en pleno auge mundial después de la Revolución cubana.

La relación entre la CVC y los intereses de los cañicultores sería irrelevante de no ser porque, durante décadas, miembros de las familias dueñas o asociadas a los ingenios, como los Carvajal, Caicedo, Garcés, Castro Borrero, entre otros, estuvieron a la cabeza de la corporación. Mediante la gestión de proyectos de interés público, las élites regionales consiguieron hacerse a importantes privilegios que han venido acumulando con el tiempo ${ }^{9}$. Proyectos como Alto Anchicayá y Salvajina se formularon durante la dirección de Henry Eder Caicedo (entre 1967 y 1976), el segundo director de la CVC y dos veces alcalde de Cali. La familia Eder, "pionera en el desarrollo agroindustrial, vinculada a proyectos estratégicos en la región y a la misma creación de la CVC” (CVC 2004, 276), ha sido históricamente dueña del Ingenio Manuelita.

La construcción de la represa Salvajina es un hito histórico presente en la memoria de los pobladores de Suárez y corregimientos circundantes (Ararat et al. 2013; Juanillo 2008a, 2008b). Con esta construcción se perdieron las mejores zonas para la agricultura y las mejores minas de oro; las actividades cotidianas ligadas al río y sus aguas (navegación, pesca, recreación y minería de aluvión) también desaparecieron. La pérdida de caminos produjo un fuerte proceso de fractura de relaciones familiares y de vecindad que habían sido construidas a lo largo de los años. Decenas de familias se desplazaron a la ciudad o buscaron otros medios de subsistencia (Juanillo 2008a, 2008b). La distribución diferencial de ventajas y desventajas generadas por la construcción de la represa hizo recaer en la población local, mayoritariamente negra e indígena, el grueso de desventajas, al tiempo que limitó el aprovechamiento de los pocos beneficios generados localmente como trabajos temporales, incremento del sector comercial

9 Para un análisis más detallado sobre la deuda social de la agroindustria de la caña en el valle del río Cauca, véase Pérez y Álvarez (2009). 
de la cabecera, entre otros. A la modificación del paisaje por la inundación se sumaron los costos sociales y culturales de la intervención sobre una población sin posibilidades reales de negociación. Las múltiples formas del despojo se hicieron evidentes: la presión para vender la tierra y su compra a precios muy bajos, la imposibilidad de contar con herramientas y recursos legales para negociar, y la poca experiencia de interacción con el dinero generaron condiciones inequitativas que apalancaron la pérdida sistemática de relaciones significativas para la vida (Ararat et al. 2013).

A inicios de los ochenta, la remoción de tierra por la construcción de la represa tuvo un efecto no calculado al dejar al descubierto grandes vetas de oro, hecho que intensificó la minería y derivó en una bonanza. En menos de tres años, la migración masiva de gente de otras veredas, de municipios cercanos y de otras regiones del país irrumpió en la cabecera de Suárez para lavar oro. Un efecto de esa situación fue la separación de Suárez del municipio de Buenos Aires y su conformación como municipio independiente en 1989. La bonanza del oro restringió la producción local de comida y redundó en escasez y subida de los precios de los bienes primarios. También aumentó el dinero circulante, el comercio, el consumo y los conflictos. Todas estas condiciones llevaron a la CVC a solicitar la militarización de la zona. Una vez el embalse estuvo lleno, cientos de personas se quedaron sin trabajo ni alternativas de subsistencia y se inició un éxodo masivo hacia Cali (Juanillo 2008b).

Otro efecto de la construcción de la represa fue el impacto en el paisaje, el clima y las formas de producción campesinas de negros e indígenas ${ }^{10}$. Salvajina cubrió algo más de $34 \mathrm{~km}$ de la cuenca alta del Cauca. Con la inundación de las zonas de cultivo, muchos pobladores negros de corregimientos como Mindalá y La Toma debieron salir a buscar ríos para minear, mientras que otros se vieron empujados a intensificar la explotación minera artesanal con nuevas técnicas de remoción superficial y lavado, y con la explotación de minas de filón (Juanillo 2008a). En poco tiempo, la economía familiar de corregimientos como La Toma empezó a depender cada vez más de la actividad minera y sus nuevas técnicas, lo que implicó la inversión en recursos como motores, plantas eléctricas y pólvora, que no todos podían costear. Esto generó nuevas desigualdades entre quienes lograron acceder y quienes no. Tales transformaciones fueron diferenciando cada vez más las prácticas productivas de los distintos corregimientos y veredas del municipio entre los más agrícolas y aquellos de vocación más minera,

10 En 1979, antes del llenado, en el área de la represa existían 613 parcelas, 342 en Buenos Aires y 271 en Morales, de entre 3 y 50 ha, dedicadas a la agricultura y la ganadería, así como las zonas de minería más importantes de la región (Juanillo 2008). 
en menoscabo de la economía familiar tradicional que combinaba agricultura y minería de aluvión.

Pureto ${ }^{11}$, una vereda del municipio de Suárez, no participó masivamente de la bonanza del oro, pero allí la construcción de la Salvajina tuvo secuelas considerables. La afectación más evidente fue la pérdida de los caminos de herradura que comunicaban la vereda con las cabeceras de Suárez, Morales y Buenos Aires. Aunque Pureto no colinda directamente con la represa, una vez se llenó el embalse los pureteños quedaron aislados y debieron buscar nuevas rutas de comunicación, pues no existían carreteras alternas. Una de las pocas compensaciones que obtuvieron las comunidades afectadas fue la adecuación del transporte fluvial gratuito una vez al día por parte de EPSA, actualmente empresa dueña y administradora de la hidroeléctrica ${ }^{12}$. Pero las regulaciones sobre la calidad del transporte son mínimas e insuficientes para suplir las necesidades de movilidad de toda la población en el área de influencia; durante las épocas de verano, los planchones no funcionan por el bajo nivel del agua, con lo cual salir y entrar de Pureto, es toda una odisea. Para los pureteños, al igual que para la mayoría de suareños, Salvajina se convirtió en un hito del despojo. Dumar Arboleda, presidente del consejo comunitario de Pureto, afirma:

Acá vinieron, hicieron lo que quisieron con el río y nos dejaron totalmente incomunicados. Montaron esto y nunca más volvieron a responder [...] mientras acá se nos trastocó la vida completa, [...] los animales se fueron, el clima cambió y en esa época que la gente no entendía bien [...]. (Entrevista, RaizAL, marzo del 2013)

11 Pureto está ubicado en la ladera de la cordillera Occidental, al sur del municipio en la cuenca del río Marilopito, tributario del Cauca. Está poblado por alrededor de ochenta familias campesinas negras y unas cuantas indígenas y mestizas dedicadas al cultivo de coca, café y algunos productos temporales para el autoconsumo. Las fincas tienen en promedio entre 2 y 3 ha y la gran mayoría carece de título formal. La historia de Pureto comienza aproximadamente en las primeras décadas del siglo XX; el proceso de poblamiento se relaciona con la presión ejercida por la concentración de la tierra en la zona plana, como con las migraciones de jornaleros del café provenientes de otras regiones. Desde el 2009, los pobladores de Pureto iniciaron el proceso para constituirse como consejo comunitario afro.

La CVC fue la única propietaria y operadora de la central hidroeléctrica hasta 1994, cuando se reestructuró esta entidad y se creó la Empresa de Energía del Pacífico S. A. (EPSA). Actualmente EPSA es privada y, desde 1996, es propietaria del embalse Salvajina. En 1997, el Gobierno vendió en subasta pública el 56,7\% de las acciones de EPSA a un consorcio formado por Houston Industries y Electricidad de Caracas. En el 2000, este consorcio cedió sus acciones a Unión Fenosa de España. En marzo del 2009, Gas Natural adquirió el 100\% de las acciones de Unión Fenosa, y se convirtió a su vez en el beneficiario real del 63,82\% de las acciones de EPSA. En el 2009, Celsia, por medio de su filial Colener, adquirió el 47,3\% de EPSA, la quinta generadora eléctrica del país. Celsia desarrolla su objeto social a través de Salvajina como una de sus centrales de generación de energía bajo control y manejo de la EPSA. La estructura societaria de Celsia se compone de Colener (100\%) y de EPSA $(50,01 \%)$ (Sentencia T-462A del 2014 de la Corte Constitucional). 
Como él, los principales líderes comunitarios de Suárez repiten una y otra vez que la construcción de Salvajina "lo que fue, fue una 'salvajada' con la población”.

En 1986 la mayoría de los afectados, directa o indirectamente, por la Salvajina eran familias negras e indígenas que se unieron en una histórica marcha hacia Popayán para solicitarles al Gobierno y a la CVC medidas de resarcimiento por los daños ocasionados (Ararat et al. 2013, 156). Pese a las narrativas desarrollistas de la CVC, la movilización cuestionó la legitimidad del proyecto ${ }^{13} \mathrm{y}$, gracias a la protesta, se firmó un acta de acuerdo entre los representantes de las comunidades y del Gobierno en la que las instituciones responsables se comprometieron a generar proyectos para mitigar el impacto de la inundación: obras públicas, infraestructura, salud y educación. En septiembre de 1986 el Gobierno emitió el Decreto 3000, mediante el cual se creó la Comisión de Supervisión y Evaluación del Plan de Desarrollo Integral de la Región de la Salvajina, cuya misión era supervisar el cumplimiento de los acuerdos y proyectos consignados en el acta. Pero dicha comisión no se conformó y los acuerdos fueron sistemáticamente incumplidos por el Gobierno y las empresas propietarias de la represa.

Las formas de resistencia frente al despojo fueron muchas. Los procesos de movilización social se derivaban de las lógicas propias de la protesta campesina de las décadas anteriores, en la que la lucha por la tierra era el centro, pero se fortalecieron al hacer sinergia con los movimientos cívico-populares que emergieron en la zona plana desde los setenta, y que pusieron en evidencia los procesos de despojo, empobrecimiento y exclusión de derechos básicos de ciudadanía, como el trabajo, los servicios públicos y la vivienda (Hurtado 2001). La movilización de 1986 representa un hito en las formas de resistencia de los pobladores frente al despojo donde, de acuerdo con la memoria de quienes participaron, la identidad campesina mantenía un especial valor y la diferenciación étnica aún no aparecía como un referente organizativo ${ }^{14}$ (Ararat et al., 2013).

Durante los años posteriores al llenado de la represa, llegaron a Pureto los técnicos cafeteros de la CVC y, con ellos, los paquetes tecnológicos para el cultivo de una nueva variedad de café con la que se esperaba reemplazar el tradicional arábigo y el caturra. La variedad Colombia incrementó la producción y la vereda se convirtió en la principal productora de Suárez, pese a las dificultades para llegar al mercado. Mediante la afiliación al comité de cafeteros, los campesinos obtenían

13 En esa misma época se creó la Asociación Pro Damnificados de Salvajina (Asoprodasa).

14 A diferencia de otras regiones, las políticas de la identidad étnica aquí aparecieron, entre otras cosas, como efecto del multiculturalismo de Estado posterior a la promulgación de la Ley 70 de 1993. 
la cédula cafeter ${ }^{15}$ con la que podían acceder a asesorías, créditos e innovaciones técnicas, como la máquina despulpadora; también a los insumos que incluían semillas mejoradas y agroquímicos, que se impusieron a pesar de los elevados costos de transporte y las dificultades de acceso al mercado a causa de la Salvajina. Pero en esta misma época aparecieron plagas como la roya y la broca que afectaron los cultivos de café, y el pasador, en el caso del plátano. La mayoría de los pobladores son claros en afirmar que todas esas afectaciones a los cultivos se debieron a la represa, particularmente, al cambio en el clima que trastocó la temperatura regional. A pesar de las iniciativas productivas impulsadas por la CVC, la crisis del sector campesino en Pureto vivió su peor momento a mediados de los noventa.

Proyectos de "modernización productiva", como la tecnificación del cultivo del café, jalonados por la prerrogativa del "desarrollo" y agenciados por distintas instituciones estatales, sirven como articuladores de la localidad con la escala regional. Pero son articulaciones constituidas sobre la base de un acumulado de desventajas estructurales que conjugan diferentes formas de exclusión y acaparamiento de oportunidades (Reygadas 2008). Por una parte, el efecto de las bonanzas suele ampliar las brechas de desigualdad económica: la sobreexplotación del trabajo de la minería artesanal durante el auge del oro en Suárez acrecentó la ganancia de los intermediarios (compradores provenientes de otras regiones), quienes además salieron rápidamente del municipio, sin que dicha ganancia se revirtiera en la localidad.

Por otra parte, se trata de intervenciones que suponen hacer tábula rasa de lo que existía previamente, hecho que priva a la gente de los beneficios que se desprenden del conocimiento local y los saberes agrícolas transmitidos de generación en generación. Como afirmó don Crescencio Flor, líder histórico de la vereda, a propósito de la llegada de la variedad Colombia: "Tuvimos que aprender de cero todo. Lo que uno sabía no servía para sembrar ese nuevo café [...]" (entrevista, junio del 2013). Esto no solo introduce a los pobladores en nuevas redes de mercado, sino que promueve la dependencia de la asesoría externa y una relación desigual frente a las lógicas de monetización y de crédito, entre gente con poca o ninguna relación con el sistema bancario. En esta época, los préstamos que ofrecía la Caja Agraria para incentivar el cambio productivo fueron un arma de doble filo para los campesinos: "La gente nunca había recibido plata y eso la entusiasmaba, pero tampoco sabía los riesgos que traía el recibirla. Mucha gente perdió [la tierra] así”, afirma Lisifrey Ararat, líder de La Toma (entrevista, enero del 2014). 
La marginalización de la mayoría de la población negra por efectos de Salvajina contrasta con los privilegios ganados por algunos comerciantes ${ }^{16}$ asentados en la cabecera municipal y por los técnicos y empleados de la CVC, pero sobre todo por los dueños de los ingenios de la zona plana y los inversionistas del proyecto de la represa, que redujeron al mínimo los costos de transacción (Rojas 2014; Vélez y Vélez 2012).

El proyecto hidroeléctrico de Salvajina demostró que entre los beneficiarios nunca se contempló a las poblaciones aledañas a la represa, mayoritariamente familias negras e indígenas. Salvajina fue pensada y construida para suplir la demanda eléctrica de una región con importantes concentraciones urbanas - Cauca, Valle, Caldas-y actualmente vende energía al extranjero ${ }^{17}$. Pureto solo tuvo acceso a la electricidad en el 2007, veinte años después de la puesta en funcionamiento de la hidroeléctrica y de innumerables gestiones frente a la Administración municipal por parte de la Junta de Acción Comunal y de la comunidad, que debió transportar y levantar los postes de energía por su cuenta. Aún hoy la calidad del servicio en la vereda es deplorable, no cubre todas las viviendas y muchas de las conexiones son piratas.

Así, el proyecto de infraestructura no solo ocupó el espacio de la gente sino que, promovido por narrativas de modernización y desarrollo regional, y generador de altas expectativas por el mejoramiento de la calidad de vida en una vasta región, en realidad fue un muy efectivo dispositivo de exclusión de las comunidades locales. El discurso de la "promoción social" de la CVC alrededor de la represa demostró ser todo lo contrario ${ }^{18}$. Si bien no era un discurso racializante, el proyecto tuvo efectos racializados en la medida en que afectó directa y desproporcionadamente a poblaciones negras e indígenas (Wade 2011). Con la obra se desprendió todo un proceso de marginalización, que derivó en ilegalización desde el momento mismo en que la gente de Pureto debió ingeniarse todo tipo de estrategias piratas para acceder a la electricidad. Hoy en día nadie responde por la calidad de la electricidad en la vereda, pues la misma prestadora de servicio aduce que la mayoría de las conexiones son ilegales. En ese sentido, vemos cómo la disputa por la circulación, el acceso y la distribución de bienes materiales y comercio de la cabecera municipal, sobre todo, los graneros. originan en nueve centrales hídricas, entre ellas, Salvajina. económica regional y generadores de empleo e inclusión social (CVC 2004, 179). 
servicios también se da en torno al poder de decidir sobre lo propio dentro de la legalidad o por fuera de ella.

Salvajina se consolida así como un ensamblaje de procesos burocráticos, técnicos y de expertos que diseñaron, construyeron, gestionaron y actualmente administran la hidroeléctrica. Este ensamblaje constituye la materialidad del modelo de desarrollo regional que ha generado el despojo de los pobladores locales, en su mayoría negros e indígenas. Al hacer evidente que el desarrollo no es para todos, sino para algunos, el modelo demuestra ser un efectivo mecanismo de marginalización con efectos de racialización, que a su vez pone en marcha dispositivos de ilegalización. Estos efectos y sus vínculos con el modelo han sido fácilmente invisibilizados durante los últimos treinta años. Esa es una de las potencialidades del despojo en la larga duración. De igual forma, el acaparamiento de oportunidades por parte de los beneficiarios directos de Salvajina — sus dueños sucesivos - ha pasado por la generación de privilegios ligados al control de instituciones como la CVC, en beneficio de intereses privados velados por los intereses del "progreso regional". Estos privilegios derivan de los réditos de la empresa y su valorización en treinta años, de la inexistencia en su momento de controles ambientales y sociales, de la falta de veeduría por parte del Estado y del incumplimiento sistemático de los acuerdos hechos con las comunidades afectadas. En lo local las desventajas acumuladas en distintos momentos y con ritmos diversos se potencian y hacen irreversibles las desigualdades entre el campo y la ciudad. Es en ese sentido que una importante dimensión del privilegio se refiere a la capacidad, derivada de la apropiación desigual, de decidir sobre la vida de los otros (RaizAL 2016a).

\section{Vida campesina: marginalización, exclusión e ilegalidad}

\section{Pureto: coca y acaparamiento}

El norte del Cauca históricamente ha albergado cultivos de coca ${ }^{19}$, aunque las variedades, usos y formas de producción han cambiado en los últimos años. La

19 La hoja de coca ha sido consumida por campesinos indígenas, negros y mestizos con fines medicinales y rituales. Proscrita por las autoridades desde la Colonia temprana, la práctica indígena de masticar o mambear la coca estaba extendida por todo el suroccidente colombiano hasta bien entrado el siglo XX. Hasta 1940 era común el pago de jornales con hojas de coca; 
crisis económica que vivió el país a mediados de los años noventa afectó dramáticamente la producción campesina en veredas como Pureto y los precios de los productos agrícolas se fueron a pique. Muchos jóvenes de la vereda salieron a buscar trabajo en Suárez, Cali y el Quindío; otros llegaron hasta el Yarí y el Caguán en el Caquetá a trabajar en ganadería, y algunos se fueron a probar suerte en el Alto Naya. En estos dos últimos lugares aprendieron a sembrar y a "raspar" coca. A inicios de la década del 2000 muchos regresaron a Pureto. La masacre paramilitar del Alto Naya en el 2001 y el levantamiento de la zona de distensión con la guerrilla de las FARC en el 2002 fueron dos hechos claves que activaron el retorno. Para entonces, la presencia activa de actores armados (guerrillas y paramilitares) en el norte del Cauca fue asumida por las entidades gubernamentales, las instituciones y algunas empresas con intereses forestales, como Cartón Colombia, como una fuerte razón para excusar la falta de inversión e incluso para solicitar mayor presencia militar.

Quienes regresaron en esa época debieron enfrentar no solo los bajos precios de sus productos en el mercado, sino las plagas en los cultivos (el pasador o perforador del tallo acabó prácticamente con el plátano; la broca disminuyó al mínimo la producción de café variedad Colombia y la baja del precio de la panela obligó a abandonar el cultivo de la caña). Estos fueron años de una muy exigua inversión pública y privada en la región y la vida cotidiana empezó a demandar más dinero circulante a medida que se hacía menos rentable la producción agrícola. A pesar de que el trabajo temporal en el barequeo, como cosecheros o en la ciudad han sido prácticas frecuentes por varias generaciones, la venta de trabajo por jornal se volvió un imperativo al tiempo que se dedicaba trabajo a la finca familiar.

Junto con aquellos que regresaron a la vereda llegaron algunos "pastusos" mestizos, provenientes del sur del país, con capitales que les permitieron adquirir lotes baratos en las partes bajas para sembrar coca y comprar la hoja a muy buenos precios. Los llegaderos introdujeron la variedad pinga o tinga proveniente de Argelia y el Plateado en el Cauca, y también vendían la semilla. En menos de cuatro años toda la vereda se volvió cocalera y llegaron jornaleros de otras regiones. Así lo afirma un líder comunitario: “[...] en el 2005 la gente empezó a sembrar coca. Empezó por antojo, porque veían cómo se sacaba harta plata y rápido, pero también por miedo de ser señalados de sapos si no lo hacían”.

incluso en 1947, cuando se prohibió esta práctica por ley, los latifundistas caucanos fueron los primeros en protestar y desacatarla (Henman 2011). De allí que en zonas aisladas como Pureto, la "pesada" o "manotada" de hoja se mantuviera como parte del pago del jornal hasta finales de los años ochenta. Aún es posible encontrar mambeadores negros que cosechan la variedad endógena, conocida como "pajarita", para su propio consumo. 
Entre el 2007 y el 2009 la producción de hoja de coca se triplicó. La cosecha, que tradicionalmente se hacía hoja por hoja, se cambió por el raspado que conocían quienes venían de zonas cocaleras. Algunos llegaderos compraron la producción local para transportarla hacia otros corregimientos donde estaban las cocinas dedicadas al procesamiento químico y construyeron laboratorios para el secado y picado de la hoja. Las técnicas se refinaron: de picar la hoja con palín se pasó a hacerlo con guadaña. Con precios en ascenso y cosechas cada dos meses y medio -la hoja alcanzó un precio de 90.000 pesos por arroba en el 2006 y se estabilizó con un promedio de 60.000 hasta el 2009-, los pureteños se volcaron hacia el cultivo. La coca demandaba inversiones importantes en abonos y agroquímicos pero los costos de producción podían ser cubiertos con las ganancias obtenidas. Con la siembra era más fácil viajar hasta Suárez por una buena remesa que dedicar parte del terreno a productos que no eran rentables. Poco a poco la coca reemplazó el espacio de los cultivos de la dieta familiar afectados por las plagas: café, frijol, vegetales, yuca y maíz.

Los altos precios de la hoja promovieron una bonanza que puso en evidencia algunos efectos del exceso de dinero circulante: el aumento de las tiendas, la llegada de compradores, comerciantes y trabajadores armados, la intensificación de las riñas y la intromisión de la guerrilla. Si bien esta zona hace parte de un amplio corredor de las FARC (Guzmán y Rodríguez 2015), la presencia guerrillera había sido esporádica en Pureto, pero frente a los conflictos cada vez más recurrentes, la guerrilla intervino restringiendo los horarios de circulación. En el 2011 una plaga, la secadera, diezmó los cultivos de coca; según los pobladores esta venía en los abonos e insumos químicos y era una estrategia contra los cultivos ilícitos, después del fracaso de las políticas de erradicación. Para contrarrestar la expansión de la plaga, se hizo “de todo” y lo que finalmente permitió lidiar con la secadera fue la introducción de la peruana, una nueva semilla mejorada, por parte de los "pastusos".

La coca es una alternativa económica viable para los pequeños agricultores que producen a pérdida debido a los bajos precios de los productos en el mercado y los altos precios de los insumos. La decisión de dedicarse al cultivo se asume como una oportunidad para mejorar las condiciones de vida, ya que permite acceder de manera rápida y comparativamente más fácil al dinero. A pesar de tener historias diferentes, en esta zona el café y la coca han generado los mismos tipos de dependencia frente a los paquetes tecnológicos (de semillas mejoradas), los insumos e incluso las formas de crédito, aunque en el caso de la coca sea de forma indirecta. Al inscribirse en una economía ilegal, la producción local de la coca se articula por otras vías con los mercados regionales, nacionales 
e internacionales. La coca no aparece en las narrativas de la modernización y el desarrollo (Ramírez 2001); al contrario, su condición supone un señalamiento moral como "la mata que mata" 20 . Sin embargo, para quienes han acogido el cultivo de la coca y entran en la cadena de producción del narcotráfico, el mercado garantizado y la producción agrícola tecnificada y eficiente se han convertido en su principal incentivo. Así, de ser una vereda agrícola pobre y aislada, Pureto tuvo una inserción rápida en la economía política del narcotráfico. La producción local no solo se engranó en la cadena productiva de la cocaína sino que este hecho insertó a los pobladores en lógicas distintas de socialización. Desde la institucionalidad se hicieron comunes narrativas sobre la presión guerrillera como causa de la expansión de los cultivos, cuando no se acusaba a los campesinos de ser la base social de la insurgencia y de tener un "gusto" por el dinero fácil.

El efecto de bonanza de la coca durante los primeros años generó ventajas económicas pero la posterior crisis que provocó la secadera puso en evidencia una serie de transformaciones de la vida campesina que los pureteños resienten como una pérdida sensible: el abandono de la mayoría de los cultivos de consumo familiar, la dependencia del mercado en Suárez para conseguir alimentos e insumos químicos y la relación con un único mercado ilegal para sacar la producción de hoja y conseguir las semillas mejoradas de nuevas variedades. De acuerdo con don Crescencio Flor:

La coca nos ha hecho ganar, pero más nos ha hecho perder. No supimos a qué hora terminamos así, cómo se nos cambiaron las cosas sin que nos diéramos cuenta... uno piensa, bueno, pues el mercado de allá abajo puede volver a funcionar, se compra el baloncito y la gente juega, pero y la amistad y el festejo ya sin con quien, porque como la mayoría ahora están en las iglesias... eso, la celebración de las madres cuando todos participaban para hacerles el almuerzo a ellas, ahí es donde uno se queda pensando qué fue lo que pasó y ahora ¿cómo es que recuperamos eso? (Entrevista en Pureto, junio del 2013)

En solo un par de años, los efectos de la nueva economía empezaron a verse en otras esferas de la vida campesina: la disolución sistemática de iniciativas y relaciones comunitarias y de los espacios de socialización de la vereda. Las mingas ${ }^{21}$, celebraciones y grupos de trabajo quedaron reducidos a su mínima expresión,

Esta frase se hizo célebre en el 2008 como parte de una campaña institucional de la Dirección Nacional de Estupefacientes contra los cultivos de uso ilícito, durante el gobierno de Álvaro Uribe Vélez. La campaña fue demandada por indígenas nasa del Cauca y la Corte Suprema ordenó retirarla de los medios en el 2010. 
pues el control de los intermediarios de la coca fue minando la autoridad de la Junta de Acción Comunal; la presencia de personas armadas trastocó los espacios de socialización habituales, como la tienda; el profesor de la escuela se fue y los técnicos cafeteros no volvieron. Las festividades tradicionales desaparecieron: el día de la Madre, las novenas al Niño y el carnaval y, con el crecimiento de las iglesias cristianas ${ }^{22}$, las fiestas y los campeonatos de fútbol se acabaron.

El dinero adquirió un valor impensable en el pasado, hecho que se reflejó en el consumo desmedido de nuevos bienes de prestigio como computadores, equipos de sonido y teléfonos celulares - a pesar de que en Pureto no hay señal-. Asimismo, las ofertas de los "pastusos" para comprar las fincas convencieron a más de uno de vender la tierra e irse a vivir al pueblo o a la ciudad. Los ideales de bienestar y de "progreso" se han fijado en la idea de dejar de ser lo que se es: irse a la ciudad y abandonar el trabajo del campo. Muchos pureteños empezaron a defender estos valores por encima de su propia forma de vida campesina. El ideal del desarrollo atraviesa los deseos de la gente y, en muchos casos, su lógica de desarraigo se impone como ideal de bienestar. Así, vemos que el despojo no es solo resultado de un ejercicio de coerción o imposición; al contrario, el consentimiento de la gente actúa de una forma igualmente efectiva en la legitimación de desigualdades sociales mediante las cuales se apalanca el despojo.

Ahora bien, lo que muestra este primer periodo de introducción del cultivo ilícito es que en pocos años los campesinos de Pureto se integraron a la nueva economía como productores independientes de hoja. Esta situación les supuso otras formas de desigualdad producto de la distribución diferencial de ventajas y desventajas: enriquecimiento económico para unos más que para otros y pérdida de relaciones comunitarias y de formas de autonomía política y cultural, que afectaron todos los ámbitos de la vida campesina. A estas desventajas se sumaron las de la ilegalidad. La producción campesina dedicada al cultivo ilegal de coca inevitablemente entraña mecanismos de marginalización y exclusión que se concretan en el cerramiento de oportunidades, como el uso de vías, medios de transporte y mercados en las cabeceras municipales. El control territorial de la guerrilla en áreas donde se extendieron estos cultivos confinó zonas enteras

22 El arribo de la coca coincidió con la llegada de la iglesia El Mensaje de la Hora. La presencia de iglesias evangélicas, como la Alianza Cristiana, se puede rastrear a inicios de los años ochenta pero los cambios que estaban aconteciendo sin duda tuvieron repercusión en las creencias de la gente. Poco a poco, buena parte de los pobladores de Pureto se convirtieron a esta religión y actualmente el $70 \%$ de los habitantes de la vereda son evangélicos. El crecimiento de estas iglesias es un tema que requiere mayor investigación, sobre todo en sus articulaciones con la economía política del narcotráfico. 
e impuso restricciones en el acceso al transporte, alimentos, bienes y servicios, cuando no la amenaza directa de los enfrentamientos con el ejército.

En ese intersticio se asentaron las estructuras medianas del narcotráfico que empezaron a ejercer una nueva forma de presión, pero esta vez sobre la tierra. Con la oferta de comprar las fincas a buenos precios, los "pastusos” se fueron haciendo a nuevos predios para ampliar el cultivo, adquirieron terrenos afectados por las plagas, extendieron sus propiedades en los corregimientos aledaños y expandieron la siembra en buena parte de la ladera. De una lógica en la que los pobladores participaban en la producción se pasó a la presión por comprarles las fincas, a veces de manera violenta, con el consecuente acaparamiento de la tierra, del producto y de la circulación de bienes (insumos, semillas, abonos). En efecto, era más rentable controlar el proceso de producción mediante la apropiación de terrenos carentes de titulación formal, la siembra directa y la contratación de raspachines, que mantener a los campesinos como productores independientes.

Otro problema que se hizo evidente fue la contaminación del agua. Los químicos de la coca llegaron al agua y afectaron la pesca y la salud de la gente, pero la situación se agravó cuando los cultivos de varios “pastusos” acapararon las quebradas y nacimientos y los contaminaron directamente. Las familias negras no solo eran despojadas del agua, sino que los mecanismos de negociación habituales (como el comité de concilio de la Junta de Acción Comunal) no funcionaban con estos nuevos vecinos llegaderos. Como lo señaló uno de los líderes del consejo comunitario, "quienes despojan no solo lo hacen porque quieren, sino también porque pueden”. Fue entonces que los líderes de Pureto tomaron la decisión de enfrentar la situación y organizarse para impedir la venta de más fincas y, como ellos mismos afirman, la pérdida del territorio. Una vez más vemos cómo la acumulación de desventajas en varios niveles genera formas de desigualdad persistente desde donde se hacen posibles nuevos despojos.

La dinamización del mercado de tierras empezó a demostrar que los empresarios ilegales o cabezas de las mafias locales y regionales provenientes del norte de Nariño y de Cali buscaban maximizar ganancias e intentaban controlar toda la producción, lo que implicaba excluir a los campesinos negros. En contraste con el modelo de producción campesino de café, la coca permite mayor acumulación y genera privilegios en distintos niveles a partir del acaparamiento de oportunidades (por ejemplo, a través del control del transporte interveredal), lo que facilita sobrellevar buena parte de las desventajas de la ilegalidad. Pero estas mafias regionales son intermediarios de quienes exportan el alcaloide y mueven el negocio internacional, lo que quiere decir que los privilegios asociados no se quedan solo allí, pues las grandes mafias articuladas transnacionalmente son 
las que reciben los más cuantiosos réditos del narcotráfico y los reinsertan legalmente en la economía nacional mediante el lavado de activos. Este, como advierte Gutiérrez Sanín (2016), ha privilegiado la compra de tierras como uno de los mecanismos más rentables de legalización de las inversiones del narcotráfico.

De nuevo, ambos dispositivos, ilegalización y marginalización de lo local, se han traducido en formas de despojo y privilegio que se combinan en un encadenamiento cuyo vínculo con el modelo de desarrollo regional pareciera inexistente. El narcotráfico está lejos de ser considerado oficialmente como un efecto articulado al modelo de desarrollo regional. Sin embargo, a pesar de tratarse de actores distintos, la lógica de acumulación por acaparamiento es básicamente la misma. Este ejemplo además advierte sobre un juego de escalas que muestra cómo el despojo generado por la economía de la coca se expresa a escala local sin lograr hacerse visible más allá del ámbito regional. En contraste, las formas del privilegio que aparecen en lo local tienen resonancia y logran trascender su visibilidad en distintas escalas y consiguen, en muchos casos, ocultar su ilegalidad. No obstante, hay que reconocer las grandes dificultades que entraña rastrear la generación de privilegios en la ilegalidad.

Ahora bien, es importante advertir que en los últimos tiempos la ampliación del control sobre la tierra que buscan los cultivadores de coca foráneos también se relaciona con las posibilidades que se abren con los Acuerdos de Paz firmados entre el Gobierno y las FARC, para ganar privilegios con la sustitución de cultivos y la formalización de las propiedades. En efecto, en el primer punto de los acuerdos se establecen mecanismos para la formalización de títulos de propiedad que beneficiarían a pequeños propietarios. Quienes hayan adquirido recientemente las tierras tendrán la posibilidad de recibir los títulos que los antiguos dueños jamás tuvieron. Por su parte, el punto 3 del acuerdo sobre cultivos de uso ilícito plantea la generación de mecanismos progresivos de sustitución mediante subsidios y programas productivos a los que tendrían acceso los nuevos propietarios llegaderos. Esta sería una forma de privilegio conseguido con la legalización promovida por el Estado. Desde esta perspectiva, la conexión entre despojo y privilegio demuestra que, si bien no se trata de una relación directa, causal o inmediata, en este caso la articulación entre ambos procesos sucede en la inestable frontera entre legalidad e ilegalidad, donde hay mecanismos activos de encubrimiento permanentemente. 


\section{La Toma. Minería y extractivismo}

El fenómeno de la expansión del cultivo de coca en veredas como Pureto encuentra un correlato en la expansión de la minería ilegal que comenzó a inicios de los noventa en otros corregimientos del municipio con una vocación minera más fuerte, como La Toma. Como se mencionó, la intensificación de la minería como práctica productiva fue uno de los efectos del despojo provocado por la represa. Sin embargo, con la llegada de foráneos interesados en las minas pertenecientes a las familias negras, a inicios de la década del 2000, entraron las primeras retroexcavadoras para explotar el oro en los ríos. El Ovejas ha sido uno de los ríos más afectados por este fenómeno, por lo que la comunidad de La Toma comenzó a organizarse tempranamente en función de su defensa ${ }^{23}$ (Ararat et al. 2013). Además de la minería, sobre el río también han existido al menos dos iniciativas de desviación o trasvase para aumentar el caudal de Salvajina. A principios de los noventa, el primer intento de desarrollar el proyecto se encontró con un naciente consejo comunitario que empezó a fortalecerse con esa lucha. Años más tarde, La Toma se convirtió en un referente regional de la organización comunitaria afro gracias a las acciones adelantadas en contra de la desviación del Ovejas y de las denuncias de los intereses foráneos que llegaban a explotar ilegalmente el oro y, sobre todo, de las concesiones mineras que el Gobierno había otorgado a privados, desconociendo el histórico poblamiento negro en la región (Ararat et al. 2013; Rojas 2014).

Al igual que con la coca, la expansión de esta economía ilegal llegó de la mano de foráneos. Mineros paisas mestizos y de otras regiones empezaron a comprar derechos de explotación de las minas familiares de la gente negra. Por medio de acuerdos desventajosos, ponían maquinaria (bombas, motores, etc.) a disposición de las familias dueñas de las minas a cambio de una participación en la ganancia obtenida durante la jornada. Muchas personas perdieron las minas de esta forma y terminaron migrando a la ciudad. "En esos acuerdos la gente no ha sabido negociar y terminan es regalando la mina. Son pocos los que han sabido calcular y no se han mareado con las propuestas de esa gente [...]" (entrevista

Como la mayoría del municipio de Suárez, La Toma es un corregimiento poblado históricamente por gente negra. Está ubicado entre las cuencas del Cauca y el Ovejas. El consejo comunitario, constituido formalmente en 1993, logró evitar el proyecto de trasvase del río Ovejas, propuesto dos veces por la CVC, gracias a los aprendizajes adquiridos con la Salvajina. Frente al vacío de información institucional sobre la presencia negra en la región y la amenaza de la obra, el consejo de la Toma ganó una tutela por el reconocimiento de la ocupación histórica afro. La Sentencia T-1045A del 2010 de la Corte Constitucional representa un triunfo legal frente a las pretensiones de las mineras y marca un precedente para que otros procesos organizativos, ubicados en lugares distintos al Pacífico, puedan solicitar el reconocimiento como consejos comunitarios afrodescendientes. 
con Lisifrey Ararat, enero del 2014). Esta forma de despojo se sumó a la de la minería ilegal mediana que introdujo las retroexcavadoras en el río. A principios de los noventa, la intensificación de la explotación gracias al uso de maquinaria pesada fue directamente proporcional a la agudización de los problemas sociales y ambientales para los tomeños. Como había sucedido durante la construcción de Salvajina, la bonanza tuvo efectos contradictorios: mientras se beneficiaban pequeños mineros independientes, el despojo en la vida cotidiana se hizo palpable; la destrucción del río y su entorno, la afectación de la pesca y de los usos del agua, la pérdida de soberanía alimentaria, entre otras, fueron evidentes.

La expansión de la minería ilegal coincidió además con la llegada del paramilitarismo a la región (Guzmán y Rodríguez 2015; Vélez et al. 2013). La entrada del Bloque Calima de las Autodefensas Unidas de Colombia al mando de Ever Veloza, alias HH, y su instalación en Timba, corregimiento de Buenos Aires, en el 2000, respondió al intento de copamiento militar sobre el corredor del Naya que estaba controlado por las FARC. Sin embargo, el paramilitarismo venía articulándose también al control territorial de actores privados con intereses en tierras de la zona, principalmente narcotraficantes y ganaderos pero también medianos mineros que requerían de seguridad privada. Con la reactivación de las Bacrim y las Águilas Negras ${ }^{24}$, este fenómeno se agudizó y se demostró la permisividad de la policía y las autoridades locales con los “dueños del negocio”, lo cual ha sido denunciado sistemáticamente por varias organizaciones sociales (Quiñones 2015). El control territorial desplegado por fuerzas paramilitares disparó la persecución a líderes sociales y el desplazamiento forzado, al tiempo que permitió el avance de las prospecciones mineras. Ejemplo de ello fue la arremetida contra los líderes del consejo de La Toma, cuando en el 2006 se inició la campaña en contra de los títulos mineros otorgados por el Gobierno a privados que servían como testaferros a empresas como la Anglo Gold Ashanti, con claros intereses en la minería a cielo abierto ${ }^{25}$. Como lo muestra Rojas (2014), la persecución a los líderes de La Toma se ha justificado en su señalamiento como "enemigos del desarrollo" opuestos a la entrada de inversión en la región. Este hecho ha puesto en evidencia que, además de los pequeños y medianos mineros ilegales dedicados a la explotación, había intereses de capitales transnacionales que en los contextos locales estaban asumiendo estrategias no legales para acceder a ciertas tierras (ODR 2011). El testaferrato permitía el ocultamiento de intereses de explotación minera sobre determinados territorios, a la vez que viabilizaba vínculos con actores armados 
ilegales para garantizar el acceso y cuidado de dichos intereses (Vélez et al. 2013). Así, la minería ilegal, lejos de ser un obstáculo para los intereses de la industria extractivista del oro, se convirtió en su aliada, a partir de los privilegios generados por articulaciones estratégicas entre legalidad e ilegalidad.

Ahora bien, el efecto de esta forma de despojo es que, al igual que con el cultivo de coca, muchos pobladores locales se han ido integrando a las estructuras de producción ilegal y familias enteras dependen económicamente de esa posición. El extractivismo minero se extiende y absorbe poblaciones que encuentran allí opciones económicas que las prácticas productivas tradicionales ya no les permiten. Asumiendo por su cuenta el riesgo de participar en actividades ilegales, es decir, trabajando de manera independiente, estos campesinos negros dedicados a la agricultura y a la minería redistribuyen cotidianamente ventajas y desventajas en la inestabilidad que suponen sus nuevas relaciones de producción. La fricción dentro de las organizaciones comunitarias y la pérdida de fuerza de las formas de autoridad local son un efecto inevitable pero contundente del despojo.

El despliegue del extractivismo como parte del modelo de desarrollo ha impuesto en las últimas décadas nuevas reglas de juego a través de la ilegalidad, lo que ha desplazado el campo de disputa hacia escenarios abiertamente ilegales. Si con la coca es evidente que las reglas del mercado para la producción y comercialización de la hoja hacen imposible que los pobladores locales, negros e indígenas, puedan competir (técnicamente, en acopio, procesamiento y venta), con el oro sucede algo semejante. A esto se suman los regímenes de propiedad de la tierra en una región donde el poblamiento negro ha sido históricamente invisibilizado ${ }^{26}$. La acumulación de desventajas históricas producto del despojo de estos campesinos está inherentemente ligada a su condición racializada, lo que se observa en la inexistencia de títulos de propiedad, la falta de información demográfica oficial sobre las particularidades del poblamiento negro, la historia de compra ilegítima de tierras, el desplazamiento y la apropiación ilegal, y la presión sobre los territorios que han ocupado. Todas estas son condiciones de desigualdad persistentes que les impiden competir en un mercado dinámico que se articula regional, nacional e internacionalmente, más allá de la veeduría estatal. Interior, Incoder, etc.) que pudiera dar cuenta de la presencia de gente negra en la zona. La mayoría de las fincas pertenecientes a gente negra carecen de títulos de propiedad y muchas de las zonas donde están ubicadas aún aparecen como baldíos en la cartografía oficial. Solo hasta el pronunciamiento de la Sentencia T-1045A del 2010 de la Corte Constitucional se dio un reconocimiento oficial del poblamiento negro en esta zona del Cauca. Aunque el tema de la propiedad de la tierra no se desarrolla aquí, como parte del argumento central consideramos que es una importante veta de exploración para trabajos posteriores. 
Sin embargo, no se puede desconocer que estas mismas imposiciones del mercado han funcionado como incentivo para la organización étnica de los campesinos negros de Suárez. Este fenómeno marcha de forma paralela, y también contradictoria, con el debilitamiento comunitario que deja la participación de la población en la economía extractivista del oro y la coca. Para el caso de La Toma hay que reconocer que la arremetida de la economía ilegal del oro y las formas de despojo y privilegio asociadas catalizaron el fortalecimiento organizativo de los consejos comunitarios en su lucha por el reconocimiento territorial, y como autoridades afro según la Ley 70 de 1993. Al no poder competir por un lugar en el mercado local y regional, ni por la propiedad formal de la tierra que han ocupado, la reafirmación del territorio y la reivindicación de un poblamiento histórico mediante la identidad étnica afro resultan ser no solo la mejor, sino tal vez la única vía para disputar un espacio, a pesar de las confrontaciones internas que implica con quienes están trabajando en la minera ilegal. No obstante, esto no significa que la etnización sea solo un recurso instrumentalizado por las comunidades; el autorreconocimiento afro se ha convertido en un mecanismo de reinvención y producción de sujetos políticos. En otras palabras, el despojo vivido por estas familias negras ha sido una condición de sus propias estrategias de agencia. El carácter productivo del despojo se ratifica así a través de la emergencia de nuevas subjetividades desde donde se disputa la posibilidad de reproducir la vida campesina.

La comunidad de Pureto decidió conformarse como consejo comunitario en el 2009, luego de un desencuentro con el vecino cabildo indígena nasa de Cerro Tijeras, a raíz de la pretensión de este de incorporar la vereda en su plan de resguardo. La iniciativa de conformación del consejo se inspiró en el ejemplo de La Toma y su trabajo alrededor de la Ley 70, que le ha permitido hacer frente al creciente interés sobre la tierra por parte de actores diversos. Entre tanto, Pureto vivía la crisis provocada por la avanzada de un cultivo del que dependían casi totalmente, pero sobre el que no tenían ninguna capacidad de decisión y que amenazaba directamente sus tierras. Para los líderes de Pureto, la figura del consejo les permitía blindar la vereda de las intenciones expansionistas de los "pastusos”, tanto como de las del cabildo, mediante la titulación colectiva de las fincas de la vereda, mientras se potenciaba una nueva forma de autoridad interna. Así, el consejo comenzó una cruzada por evitar la venta de las fincas, recuperar las fuentes de agua, volver al cultivo de café y establecer un mecanismo de transición entre la Junta de Acción Comunal y la junta del consejo.

La nueva figura también les permitió integrar la mesa de consulta previa y la negociación directa con la EPSA, obligada a consultar el plan de manejo 
ambiental de Salvajina con las comunidades afectadas. Los liderazgos se renovaron con la participación de jóvenes que, a pesar de la crisis, comenzaron a trabajar en la construcción del Plan de Buen Vivir27, con la idea de darle al consejo un proyecto político como organización. De esta forma se viene alimentando la capacidad narrativa para hablar de la historia propia, el poblamiento y la memoria de los viejos, pero también la reflexión política sobre las implicaciones del despojo generado por Salvajina y el cultivo de la coca y, principalmente, la amenaza que representan quienes tienen intereses en el territorio. El trabajo de estos nuevos líderes no solo ha potenciado el reconocimiento de las historias locales, sino que alimenta la producción de una historia regional contada por las organizaciones sociales y cuyo potencial político está hoy articulado a través de figuras como la Asociación de Consejos Comunitarios de Suárez y la Asociación de Consejos Comunitarios del Norte del Cauca (Aconc), con el apoyo del Proceso de Comunidades Negras (PCN).

\section{A manera de conclusión}

Los procesos de despojo a los que se han visto enfrentados los campesinos negros de Pureto y La Toma en el alto Cauca no pueden explicarse como un fenómeno de coyuntura, sino como procesos de larga duración enmarcados en la configuración regional y las disputas que ella entraña. Partimos de entender las ideas de "modernización” y "desarrollo" que hasta ahora han hecho carrera en la región como una narrativa en la que el proceso de consolidación de una economía de mercado se asume como naturalmente positivo para todos los actores involucrados. El "desarrollo" se piensa en términos inefables, se mide con indicadores que estandarizan condiciones de vida particulares y con miras a lograr un mundo conectado en redes, que no implican la reproducción y permanencia de la pluralidad de mundos, identidades y cosmovisiones en convergencia. De manera que nos encontramos frente a un escenario que ha naturalizado las condiciones de desigualdad y la reproducción de relaciones de subordinación que se fundamentan y alimentan en diferencias a partir de marcadores de clase, raza y etnia.

Si bien partimos de vincular analíticamente el despojo y el privilegio, no consideramos que esta relación sea directa e inmediata. Ambos generan y se

27 Los Planes de Buen Vivir o Planes de Vida son ejercicios de planeación comunitaria que vienen desarrollándose en el marco de las iniciativas de reconocimiento de derechos étnicoterritoriales de la población afrocolombiana de acuerdo con la Ley 70. 
alimentan de la desigualdad. En ese sentido, así como el despojo se decanta en acumulados de despojo anteriores, los privilegios se actualizan y amplían sobre la base de sedimentaciones de privilegios previos. Así, una importante dimensión del privilegio se refiere a la capacidad, derivada de la apropiación desigual, de decidir sobre la vida de los otros.

Hoy por hoy podemos afirmar que el despojo en municipios como Suárez ha sido una experiencia real articulada a la construcción de Salvajina, a la promoción del monocultivo de café y coca, a las múltiples concesiones mineras entregadas en territorios negros, a la llegada de las retroexcavadoras, a la entrada de foráneos a comprar las tierras y minas que se explotan artesanalmente, entre otros. La exclusión, el acaparamiento de oportunidades, la delegación de las decisiones, la generación de expectativas y el incumplimiento sistemático de acuerdos, entre otras, son formas de acumulación de desventajas que permiten encadenamientos históricos de despojo donde marginalización e ilegalización han jugado como dispositivos en secuencia (marginalización-ilegalización; ilegalización-marginalización).

Asimismo, la consolidación de la economía regional en manos de una élite liberal y blanca ha desestimado el componente étnico y racial que caracteriza a buena parte de la mano de obra con la que funciona, naturalizando relaciones sociales racializadas y obviando formas de discriminación histórica que impiden percibir a los pobladores locales como sujetos que se disputan el acceso a la tierra, al mercado, al trabajo digno, al consumo y al bienestar, en condiciones asimétricas. El “desarrollo" existe pero no es para todos, y en esa medida los que quedan por fuera acumulan la mayor parte de las desventajas distribuidas. Leer entonces para quiénes sí se da ese “desarrollo” nos sitúa en la labor de analizar mejor la producción de privilegios. El norte del Cauca ha sido objeto de un modelo de desarrollo regional liderado por la élite empresarial del Valle del Cauca y avalado por el Estado, dirigido a articular lo local con la esfera regional, nacional e internacional. Este modelo fundado en la agroindustria y el extractivismo, que al menos desde hace setenta años ha sido nacionalmente reconocido como uno de los más exitosos en el ámbito nacional, se desplegó en el valle geográfico del río Cauca gracias a la CVC. Más allá de los límites político-administrativos y las circunscripciones departamentales, la labor de esta entidad promovió una relación de dependencia y subordinación entre el Valle y el norte del departamento del Cauca, alentada por el empresariado valluno, cuyas iniciativas de expansión y control territorial han considerado el norte del Cauca como parte de sus dominios. Tal vez el estereotipo nacional que posiciona al Cauca como "zona roja” y beligerante, bastión de la insurgencia y cuna de "indios y negros revoltosos”, haya servido 
también para invisibilizar las disputas por la hegemonía que distintos actores locales, marcados como “otros” (Segato 2007), dan en los niveles local y regional.

En ese sentido, creemos necesario profundizar en el análisis de la producción y reproducción de los privilegios en la configuración regional, generados por la materialización del modelo en eventos como la construcción de Salvajina, la agroindustria, la minería y el monocultivo. Pero, además, y de manera más profunda, es preciso examinar las reconfiguraciones generadas a través de las economías ilegales del oro y de la coca, que han puesto a su servicio actores armados legales e ilegales. Este tipo de relaciones hace especialmente relevante poner el foco sobre cómo los privilegios generados por el modelo de desarrollo extractivista incluye la ilegalidad como regla de juego y como campo de disputa. Y, en particular, cómo es que a través de esas estrategias los grandes capitales con intereses en la región sacan partido y reproducen sus privilegios en la aparente legalidad. Este trabajo reconoce sus limitaciones en esa dirección, al tiempo que propone un horizonte de análisis a futuro de la producción de privilegios en distintas escalas. Es necesario reparar, entre otros, en el papel de las élites regionales y el empresariado, en las formas de presencia e intervención del Estado, en las estructuras del narcotráfico y su economía política, y en los intereses extractivistas del capital transnacional para comprender qué tipo de privilegios se logran desde allí. En ese sentido, creemos que el análisis de las configuraciones de despojo/ privilegio resulta fundamental, justamente porque pone en evidencia formas de ocultamiento del vínculo que operan a favor de quienes obtienen los privilegios, legitimando y naturalizando su poder de decisión sobre la vida de otros.

Por otro lado, los actuales procesos organizativos alrededor de las formas de etnización promovidas por la Constitución de 1991 han transformado relaciones históricas entre poblaciones diversas que han convivido por décadas en la localidad. Sin embargo, la emergencia de los consejos comunitarios afro y su fuerza actual demuestran que, más allá de una simple instrumentalización del reconocimiento diferencial, estas comunidades se han reconstruido como nuevos sujetos políticos a partir de la adscripción étnica. Los procesos organizativos afronortecaucanos han crecido, se han consolidado y hoy están más fortalecidos que nunca, hecho que se ha demostrado en la activa participación de los consejos afro de Suárez en las recientes movilizaciones sociales de la Cumbre Agraria en el Cauca, en junio del 2016, y las posteriores negociaciones con el Gobierno. La visibilidad del caso de La Toma a escala nacional pero, sobre todo, internacional, ha hecho que el problema de la minería ilegal no solo sea reconocido sino que se haya posicionado en la agenda del movimiento social como "el problema" de las comunidades negras de la cuenca del alto Cauca (ODR 2011). Si bien sería absurdo 
desconocer el impacto de la minería ilegal en la región, lo cierto es que los efectos de la inmersión en la economía política de la coca también han impactado con fuerza a las comunidades afro dedicadas a la agricultura. Aunque los consejos comunitarios afro estén buscando consolidarse más allá de la vocación productiva de sus comunidades y los procesos étnicos hayan ganado peso, las condiciones en las que estos campesinos se están enfrentando al modelo de desarrollo extractivista no tienen actualmente la misma visibilidad hacia afuera. Falta ver el efecto de las negociaciones entre las FARC y el Estado y las particulares formas en que se implementen esos acuerdos en la zona.

En conclusión, en los últimos cuarenta años los efectos despojadores y racializados de Salvajina han reforzado otras formas de desigualdad y de despojo sobre la vida campesina de la gente negra en el alto Cauca. Estas comunidades se han enfrentado a la imposibilidad de defender formalmente la posesión de sus tierras frente a los intereses de terceros foráneos y han sufrido una creciente exclusión de los mercados más activos, tanto legales como ilegales, al no poder competir individualmente con los grandes productores de coca y oro. En ese sentido, los procesos de etnización dan cuenta del carácter productivo del despojo/ privilegio en la región. Las políticas multiculturalistas toman fuerza en la medida en que legitiman, al menos en parte, la posesión de la tierra y permiten agenciar colectivamente (no individualmente) la competencia económica con otros actores $^{28}$. Podemos entonces afirmar que el multiculturalismo etnicista no solo funciona como una política de Estado de arriba hacia abajo, sino como un campo de disputa más en la configuración regional de despojo/privilegio.

\section{Referencias}

Almario, Oscar. 2013. La configuración moderna del Valle del Cauca, Colombia, 1850-1940. Espacio, poblamiento, poder y cultura. Cali: Corporación Cívica Daniel Gillard.

Alonso, Julio y Ana María Lotero. 2006. 10 años de Ley Páez. Cali: Centro de Investigación en Economía y Finanzas (Cienfi), Universidad Icesi.

Aprile-Gniset, Jacques. 1994. Los pueblos negros caucanos y la fundación de Puerto Tejada. Cali: Gobernación del Valle del Cauca.

28 Por tratarse de una política que promueve derechos diferenciales para poblaciones étnicamente marcadas, los arreglos multiculturales lo que hacen es legitimar unas formas de desigualdad sobre otras. En este caso, la diferencia etnizada y racializada de la gente negra e indígena de Suárez pasa a redefinir la distribución de derechos. No obstante, esto sucede a condición de generar otro tipo de desigualdades frente a poblaciones sin marcación étnica. 
Ararat, Lisifrey, Ana María Solarte, Axel Rojas, Gildardo Vanegas, Aníbal Vega, Aduar Mina y Luis Armando Vargas. 2013. La Toma. Historias de territorio, resistencias y autonomía en la cuenca del alto Cauca. Popayán: Consejo Comunitario Afrodescendiente de La Toma; Observatorio de Territorios Étnicos, Pontificia Universidad Javeriana.

Bourdieu, Pierre. 2012. La distinción. Criterio y bases sociales del gusto. México D. F.: Taurus.

Corporación Autónoma Regional del Valle del Cauca (CVC). 2004. Génesis y desarrollo de una visión de progreso: CVC 50 años. Cali: CVC.

Das, Veena y Deborah Poole. 2008. “El Estado y sus márgenes. Etnografías comparadas”. Revista Académica de Relaciones Internacionales 8: 19-52.

Edelman, Marc. 2013. "What is a Peasant? What are Peasantries? A Briefing Paper on Issues of Definition”. http://www.ohchr.org/Documents/HRBodies/HRCouncil/WGPleasants/Edel man.pdf.

Escobar, Arturo. 1998. La invención del tercer mundo. Bogotá: Norma.

Friedemann, Nina S. de. 1976. "Negros: monopolio de tierras, agricultores y desarrollo de plantaciones de caña de azúcar en el valle del río Cauca”. En Tierra, tradición y poder en Colombia. Enfoques antropológicos, editado por Nina S. de Friedemann, 143-167. Bogotá: Colcultura, Biblioteca Básica Colombiana.

Gudeman, Stephen. 2013. “La energía vital. La corriente de relaciones”. Antípoda 17: 25-47.

Gutiérrez Sanín, Francisco. 2016. Conferencia de Apertura de la Conferencia Internacional “Tierras y territorios en las Américas: acaparamientos, resistencias y alternativas”. Universidad Externado de Colombia, 23-26 de agosto del 2016.

Guzmán, Álvaro y Alba Nubia Rodríguez. 2015. Orden social y conflicto armado: el norte del Cauca 1990-2010. Cali: Univalle.

Henman, Anthony. (1975) 2011. Mamacoca. Popayán: Universidad del Cauca.

Hurtado Saa, Teodora. 2001. "Treinta años de protesta social: el surgimiento de la movilización ‘étnica' afrocolombiana en el norte del Cauca”. En Acción colectiva, Estado y etnicidad en el Pacífico colombiano, editado por Mauricio Pardo, 95-122. Bogotá: Instituto Colombiano de Antropología e Historia; Colciencias.

Ingold, Tim. 2000. “Culture, Nature, Environment. Steps to an Ecology of Life”. En The Perception of the Environment, 13-26. Londres y Nueva York: Routledge.

Juanillo Mina, Ismael. 2008a. Salvajina, oro y pobreza. Cali: Ismael Juanillo Mina.

-. 2008b. Los otros desplazados en Colombia. Cali: Ismael Juanillo Mina.

Observatorio de Discriminación Racial (ODR). 2011. La disputa por los recursos naturales en los territorios afrocolombianos. El caso de Buenos Aires y Suárez (Cauca) desde una perspectiva de derechos humanos. Bogotá: Universidad de los Andes; PCN; Dejusticia.

Pérez, Mario Alejandro y Paula Álvarez. 2009. Deuda social y ambiental del negocio de la caña de azúcar en Colombia. Responsabilidad social empresarial y subsidios implícitos en la industria cañera. Análisis en el contexto del conflicto corteros-empresarios. Bogotá: Semillas; Swissaid; Appleton Fundation; SSPN. 
Quiñones, Aída. 2015. "Geopolítica de los conflictos socioambientales: resistencia a la expansión minera”. Revista Memoria y Sociedad 19 (39): 73-92.

RaizAL-Centro del Pensamiento Latinoamericano. 2016a. "Apuntes sobre procesos de despojo/privilegio”. Intervenciones en Estudios Culturales 2 (jul.-dic. 2015): 35-41. http://biblioteca.clacso.edu.ar/clacso/se/20160512102848/inter2.pdf.

—. 2016b. "Reflexiones preliminares sobre el privilegio". Documento de trabajo.

Ramírez, María Clemencia. 2001. Entre el Estado y la guerrilla. Identidad y ciudadanía en el movimiento de los campesinos cocaleros del Putumayo. Bogotá: Instituto Colombiano de Antropología e Historia.

Reygadas, Luis. 2008. La apropiación. Destejiendo las redes de la desigualdad. México D. F.: Anthropos; Universidad Autónoma Metropolitana, Iztapalapa.

Rojas, Axel. 2014. "De la salvación al desarrollo: gente negra, evangelización y extractivismo en el suroccidente colombiano”. Revista de Historia Comparada 8 (1): 59-95.

Rojas, José María. 1985. Sociedad y economía en el Valle del Cauca: empresarios y tecnología en la formación del sector azucarero en Colombia 1860-1980. Bogotá: Universidad del Valle; Biblioteca del Banco Popular.

Salgado, Carlos. 2002. Los campesinos imaginados. Bogotá: Instituto Latinoamericano de Servicios Legales Alternativos (ILSA).

Scott, James. 1976. The Moral Economy of the Peasant: Rebellion and Subsistence in Southeast Asia. New Haven y Londres: Yale University Press.

Segato, Rita Laura. 2007. “Identidades políticas, alteridades históricas”. La nación y sus otros. Buenos Aires: Prometeo.

Taussig, Michael. (1980) 1993. El diablo y el fetichismo de la mercancía en Sudamérica. Buenos Aires: Nueva Visión.

Taussig, Michael y Anna Rubbo. (1975) 2011. Esclavitud y libertad en el valle del río Cauca. Bogotá: Universidad de los Andes.

Urrea, Fernando, Álvaro Guzmán, Jorge Hernández, Mario Luna y Luis Carlos Castillo. 2010. Etnicidad, acción colectiva y resistencia: el norte del Cauca y el sur del Valle a comienzos del siglo XXI. Cali: Universidad del Valle.

Van Young, Erik. 1991. "Haciendo historia regional: consideraciones metodológicas y teóricas”. En Región e historia en México (1700-1850). Métodos de análisis regional, compilado por Pedro Pérez Herrero, 255-281. México D. F.: Instituto Mora; Universidad Autónoma Metropolitana.

Vanegas, Gildardo y Axel Rojas. 2011. Territorios negros en el norte del Cauca. Contexto político-organizativo. Bogotá: Observatorio de Territorios Étnicos (OTE), Pontificia Universidad Javeriana.

Vélez, Irene, Daniel Varela, Sandra Rátiva y Andrés Salcedo. 2013. "Industria agrícola y extractivismo en el alto Cauca: impacto sobre los sistemas de subsistencia afrocampesinos y resistencias (1950-2011)”. CS 12 (2): 157-188. 
Vélez, Irene e Hildebrando Vélez. 2012. "Acaparamiento del agua y despojo de la tierra en el alto Cauca: estudio crítico sobre (in)justicia hídrica y derecho al agua en Colombia”. http:// www.canadians.org/sites/default/files/publications/RTWColombia-1.pdf.

Wade, Peter. 2011. "Multiculturalismo y racismo”. Revista Colombiana de Antropología 47 (2): 15-36.

West, Robert. 1972. La minería de aluvión en Colombia durante el periodo colonial. Bogotá: Imprenta Nacional. 